\title{
GELANGGANG REMAJA DI MUARA TEWEH (MUARA TEWEH YOUTH CENTERS)
}

\author{
Findara Illa Nursyifa \\ Program Studi Teknik Arsitektur Fakultas Teknik Universitas Lambung Mangkurat \\ findara.in@gmail.com
}

Pakhri Anhar

Program Studi Teknik Arsitektur Fakultas Teknik Universitas Lambung Mangkurat pakhrianhar@ulm.ac.id

\begin{abstract}
ABSTRAK
Pentingnya Pendidikan non-akademik bagi para remaja dinilai tidak kalah penting dalam rangka agar berkembangnya berbagai potensi yang ada dalam diri mereka. Para remaja di Muara Teweh dinilai cukup antusias dalam mengikuti berbagai jenis kegiatan tersebut. Namun, terdapat beberapa yang diketahui sering menjadi penghambat diantaranya yaitu tidak tersedianya wadah maupun fasilitas serta lingkungan yang cenderung determinatif. Sehingga ditakutkan akan mengurangi ketertarikan remaja dalam mengeksplorasi potensi minat dan bakat mereka secara lebih leluasa. Hal ini menjadi latar belakangnya perlunya pengadaan tempat berupa youth center yang berperan untuk mewadahi kegiatan pengembangan tersebut namun juga menawarkan suasana kawasan yang menyenangkan, tidah kaku, dinamis dan fleksibel, agar para remaja dapat dengan nyaman melakukan kegiatannya. Metode pendekatan yang dilakukan yaitu melalui Pendekatan Psikologi arsitektur dengan memperhatikan karakteristik remaja sebagai acuan perancangan. Hal ini diwujudhan dengan konsep youth cultural space yang diterapkan pada elemen-elemen arsitektur baik pada ruang dalam maupun ruang luar.

Kata kunci: Menyenangkan, Dinamis, Fleksibel, Psikologi Arsitektur, Youth Cultural Space.
\end{abstract}

\section{ABSTRACT}

The importance of non-academic education for teenagers is considered no less important in order to the development of various potentials within them. Teenagers in Muara Teweh were considered quite enthusiastic for participating in various types of activities. However, there are some that are known to be frequent obstacles, including the unavailability of place and facilities, and environments that tend to be determinative. This situation is feared will reduce the interest of teenagers to exploring their potential interests and talents more freely. This is the background of the need to procure a place in the form of a youth center that has a function for accommodating these development activities but also offers a fun atmosphere, dynamic and flexible, so that teens can comfortably carry out their activities. The method that is used is an architectural psychology approach by observing the characteristics of teenagers as a design reference. This is manifested by the concept of a youth cultural space that is applied to architectural elements in both indoor and outdoor space.

Keywords: $\quad$ fun, dynamic, flexible, architectural psychology, youth cultural space. 


\section{PENDAHULUAN}

Berdasarkan Undang-Undang Nomor 20 Tahun 2003 Tentang Sistem Pendidikan Nasional pendidikan tidak hanya terpaku pada pembelajaran akademik, pendidikan non akademik dalam bidang pengembangan potensi diri juga dinilai tidak kalah penting agar peserta didik memiliki pengetahuan keagamaan, pengendalian diri, kepribadian, kecerdasan, akhlak mulia, serta keterampilan yang diperlukan dirinya, masyarakat, bangsa dan negara.

Secara umum, saat ini sekolah-sekolah lebih menekankan prestasi peserta didik hanya pada bidang akademik, sehingga presentasi pembelajaran non akademik lebih sedikit. Tekanan yang dirasakan para peserta didik disekolah membuat mereka kewalahan dan kelelahan, sehingga mereka kurang menyadari adanya potensi lain dalam dirinya yang juga dapat dikembangkan. Bahkan tidak sedikit dari mereka yang mengenyampingkan minatnya kemudian beralih pada kegiatan seperti contohnya nongkrong, balapan liar, berkumpul dengan kelompok-kelompok tidak jelas (geng), pergi ke pusat perbelanjaan, dsb guna mengisi waktu luang, mengingat remaja cukup rentan dalam berbagai pengaruh negatif, Ditambah dengan dunia mereka (dunia remaja) memang sarat akan kebebasan untuk melakukan aktivitas dan keinginannya sendiri dengan bersantai dan bergembira.

Mengikuti berbagai macam

komunitas non akademik maupun organisasi umumnya menjadi salah satu tujuan remaja dalam mengisi waktu luang. Hal tersebut juga bertujuan untuk mencegah remaja melakukan perilaku-perilaku menyimpang. Kegiatan non-akademik umumnya dikaitkan pada kegiatan dalam rangka mengembangkan minat dan bakat baik yang bersifat pertandingan, perlombaan, maupun

hanya sekedar untuk menyalurkan hobi. Kegiatan pengembangan minat dan bakat tersebut umumnya dapat dikategorikan pada bidang olahraga, bidang seni seperti maupun bidang lain. Berikut tabel data mengenai kegiatan non-akademik untuk cabang olahraga dan seni yang digemari oleh para remaja di Muara Teweh.

Tabel 1. Data Cabang Olahraga dan Seni

\begin{tabular}{|c|c|c|}
\hline No & $\begin{array}{l}\text { Cabang } \\
\text { Olahraga }\end{array}$ & Venue Latihan \\
\hline 1 & Bola Basket & $\begin{array}{l}\text { Lapangan Basket di } \\
\text { Stadion Swakarya }\end{array}$ \\
\hline 2 & Bola Volley & $\begin{array}{l}\text { Lapangan Volley d Stadion } \\
\text { Swakarya }\end{array}$ \\
\hline 3 & Atletik & $\begin{array}{c}\text { Track Lari di Stadion } \\
\text { Swakarya }\end{array}$ \\
\hline 4 & Tenis Meja & Gedung Kebakaran \\
\hline 5 & Sepatu Roda & \multirow{2}{*}{$\begin{array}{c}\text { Arena Terbuka Tiara } \\
\text { Batara }\end{array}$} \\
\hline 6 & Skate Board & \\
\hline 7 & Bulu Tangiks & \multirow{3}{*}{ GOR Muara Teweh } \\
\hline 8 & Karate & \\
\hline 9 & Senam & \\
\hline 10 & Bridge & \multirow{3}{*}{ KONI Muara Teweh } \\
\hline 11 & Catur & \\
\hline 12 & SKB Tinju & \\
\hline 13 & Panahan & $\begin{array}{c}\text { Dibelakang lokasi site } \\
\text { terpilh }\end{array}$ \\
\hline 14 & Panjat Tebing & $\begin{array}{c}\text { Arena Panjat Tebing TRR } \\
\text { Muara Teweh }\end{array}$ \\
\hline 15 & Dansa & Aula Kantor BLH \\
\hline 16 & Futsal & Lapangan Indoor Excellent \\
\hline 17 & Dayung & Sungai Barito \\
\hline 18 & Renang & Tidak tersedia \\
\hline 19 & $\begin{array}{l}\text { Sanggar Tiung } \\
\text { Gomba }\end{array}$ & $\begin{array}{l}\text { Aula Sanggar Milik } \\
\text { Sanggar Pribadi }\end{array}$ \\
\hline 20 & $\begin{array}{l}\text { Sanggar Tari } \\
\text { Malawen } \\
\end{array}$ & \\
\hline 21 & $\begin{array}{l}\text { Sanggar Tan } \\
\text { BKT }\end{array}$ & Rumah Pribadi Pelatin \\
\hline
\end{tabular}

Sumber: Ilham kurniawan, Atlet Cabang Atletik dan Karate Muara Teweh serta Eriza Riris,

Penari Tradisional dan Modern

Kemudian diketahui Muara Teweh sebagai ibukota Kabupaten Barito Utara cukup aktif mengirimkan remaja-remaja daerah untuk menjadi perwakilan dalam kegiatan Festival Budaya Isen Mulang yang rutin setiap tahun diadakan dengan cabang- cabang lomba tradisional baik dalam bidang olahraga maupun dalam bidang industri kreatif lokal dalam rangka melestarikan kerajinan-Budaya khas daerah.

Dilihat dari isu serta tabel diatas, dapat dinilai remaja di Muara Teweh cukup antusias untuk mengikuti kegiatan non- akademik untuk pengembangan minat dan bakat mereka. Namun terlepas dari antusiasme para remaja untuk mengikuti kegiatan-kegiatan tersebut, dalam hal ini keberadaan tempat latihan dan situasi tempat latihan sering kali menjadi penghambat. Menurut pernyataan Ilham Kurniawan seorang atlet cabang atletik dan karate, sering kali terjadi selisih 
paham antar cabor dikarenakan fasilitas yang tersedia merupakan fasilitas umum sehingga mereka saling berebut tempat untuk mengadakan latihan atau tempat tersebut sedang digunakan oleh pihak Lain yang mengakibatkan latihan tidak jadi diadakan. Bahkan sering kali mereka menggunakan gudang yang diketahui bukan tempat yang kondusif sebagai tempat latihan. Selain itu situasi yang determinatif saat latihan membuat remaja kurang bebas dalam mengekspresikan bakat nya. Sejauh ini faktor-faKTor tersebut cukup menjadi permasalahan yang semakin ditakutkan akan menyebabkan berkurangnya minat para remaja untuk mengembangkan bakatnya.

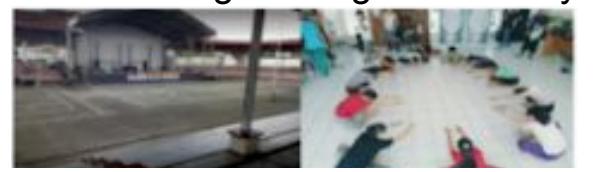

Gambar 1. Suasana tempat latihan kegiatan

Kemudian menilai dari karakter yang dimiliki oleh seorang remaja, situasi yang determinatif bukan merupakan suasana yang nyaman untuk mereka beraktivitas. Remaja cenderung memiliki jiwa kebebasan dan melakukan kegiatan mereka dengan diiringi kegembiraan sehingga memerlukan sebuah distraksi. KaraMer tersebut perlu dipertimbangkan dalam merancang sebuah wadah pengembangan minat dan bakat untuk remaja. Distraksi tersebut dapat berupa lingkungan atau situasi yang dapat menciptakan suasana yang menyenangkan dan fleksibel. Sehingga dalam hal ini youth center bukan hanya wadah yang bersifat edukatif namun juga menawarkan suasana kawasan yang rekreatif bagi para remaja.

Kehadiran youth center di Muara Teweh diharapkan dapat menjadi sebuah wadah pengembangan yang menyenangkan dan mampu menstimulasi minat dan bakat para remaja. Youth Center menjadi tempat untuk membantu mengembangkan kemampuan fisik, sosial, dan emosional agar timbulnya semangat prestasi, kepemimpinan, persahabatan pada generasi muda di Muara Teweh. Sehingga hal ini dapat menjadi salah satu penunjang dalam perkembangan pembangunan dan sumber daya manusia yang lebih baik untuk Kota Muara Teweh.

\section{PERMASALAHAN ARSITEKTUR}

Bagaimana desain perancangan youth center yang dapat mewadahi dan mampu menstimulasi minat dan bakat remaja di Muara Teweh ?

\section{TINJAUAN PUSTAKA}

\section{A. Tinjauan Arsitektural}

Youth center terdiri dari dua kata yang mana masing-masing berarti yaitu youth adalah masa muda sedangkan center adalah pusat, bagian tengah, pokok, pangkal. Sehingga secara umum youth center dapat diartikan sebagai pusat yang mewadahi kegiatan positif kreatif para anak muda yang dalam hal ini kita sebut sebagai remaja. Dalam bahasa Indonesia youth center diartikan sebagai Gelanggang Remaja yang mempunyai makna yaitu ruang atau tempat yang biasanya dipakai para remaja untuk memanfaatkan waktu luang dengan melakukan berbagai kegiatan yang berguna (menurut Kamus Besar Bahasa Indonesia). Secara umum fungsi youth center adalah menyediakan wadah kegiatan bagi para remaja untuk mengembangkan minat dan bakat yang dimilikinya. Youth Center sebagai sarana dan prasarana kegiatan para remaja yang meliputi kegiatan mental spiritual, pengetahuan dan keterampilan, olahraga, seni, dan rekreasi.

Youth center juga dapat diartikan sebagai youth clubs yaitu tempat untuk bermain, membaca, serta mempelajari kemampuan dan keterampilan baru bagi remaja sekaligus sebagai tempat bersosialisasi yang digunakan di luar jam sekolah (Synder,1984)

Fasilitas didalam youth center terbagi menjadi 3 (tiga) yaitu :

1) Fasilitas Utama : Klub Olahraga, Klub Seni dan Klub Industri Kreatif lokal

2) Fasilitas Penunjang : youth garden, youth cafetaria, hall (aula terbuka), dsb 
3) Fasilitas Pendukung : kamar mandi/wc, dan area parkir serta ruang pengelola

\section{B. Tinjauan Konsep}

Istilah psikologi arsitektur (architectural psychology) pertama kali diperkenalkan ketika diadakan konferensi pertama di Utah pada tahun 1961 dan 1966. Perilaku pengguna mempunyai keterkaitan dengan arsitektur sebagaimana Fisher (1984) menyatakan bahwa meskipun direncanakan secara umum, rancangan arsitektur dan bangunan-bangunannya dapat mempengaruhi perilaku dan kualitas manusia penggunanya. Desain rancang bangunan youth center diselesaikan melalui pendekatan psikologi arsitektur dengan merefleksikan karakter psikis remaja secara umum ke dalam bangunan pada teori-teori dasar arsitektur sehingga mampu menciptakan suasana maupun situasi yang diinginkan.

\section{METODE}

Di Dalam arsitektur, suasana didalam ruang, bangunan dan kawasan dapat memberikan reaksi dan dampak psikis terhadap seseorang. Elemen-elemen sederhana yang dipilih sedemikian rupa pada ruang, bangunan dan kawasan berdasarkan karakteristik seorang remaja sebagai pengguna dapat mewujudkan suasana yang diinginkan. Teori-teori dasar arsitektur untuk massa dan ruang yang dapat mempengaruhi psikologi seseorang yaitu diantaranya teori bentuk dan tata massa, elemen garis, teori warna, teori sirkulasi, material dan tekstur, penataan ruang luar.

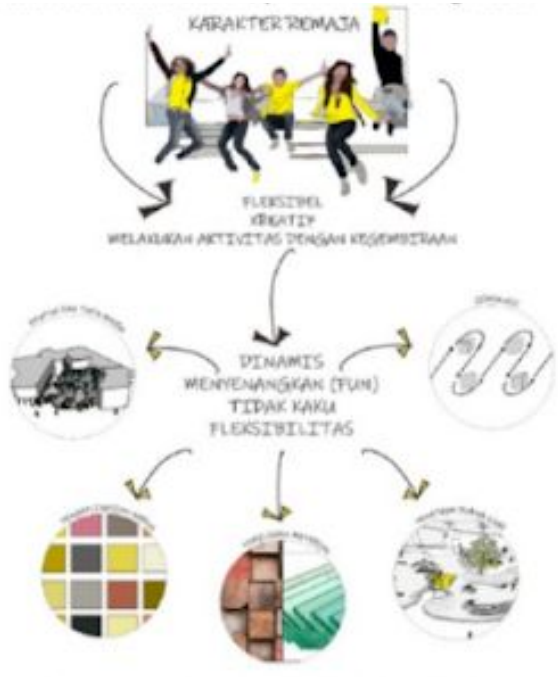

Gambar 2. Implementasi Metode Psikologi Arsitektur

\section{PEMBAHASAN}

\section{A. Konsep Programatik}

Konsep programatik adalah konsep yang akan digunakan untuk menyelesaikan permasalahan sehingga tujuan perancangan dapat dicapai. Konsep programatik menjadi acuan dan dasar dalam setiap perancangan youth center. Konsep programatik yang digunakan adalah konsep Youth Cultural Space. Konsep ini terdiri dari dua hal utama yang menjadi dasar dalam perancangan youth center yaitu sebagai berikut

1)Karakter. Yaitu karakter dari remaja secara umum yang diambil nilai-nilai nya untuk kemudian direMeksikan ke dalam ruang, bangunan, dan kawasan melalui teori-teori dasar arsitektur.

2)Cultural. Yaitu Culture (budaya) khas Kalimantan yang diterapkan baik dalam tipologi bangunan panggung maupun penggunaan motif pada bagian-bagian bangunan. 


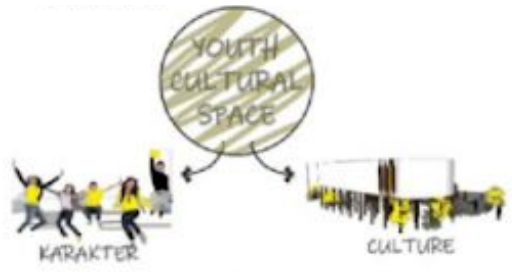

Gambar 3. Konsep Programatik

\section{B. Konsep Programatik}

Dalam hal ini konsep perancangan mencakup konsep desain bangunan dan ruang luar yang berkaitan dengan pola aktivitas dan fasilitas didalam youth center.

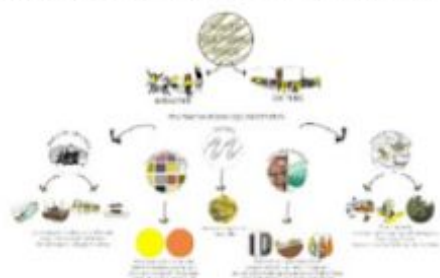

Gambar 4. Implementasi Konsep Youth Cultural Space

1. Konsep Site

Untuk mewujudkan suasana yang menyenangkan maka tata bangunan maupun ruang dirancang dengan pola-pola dinamis seperti penggunaan garis lengkung dsb. Organisasi yang digunakan dalam pola tata massa adalah organisasi cluster. Pola ini dapat diwujudkan dalam bentuk bangunan secara keseluruhan sehingga juga akan mempengaruhi pola sirkulasi di dalam bangunan maupun pada elemen-elemen arsitektur pendukung. Bangunan juga dapat disusun per zona dengan penyusunan zona sesuai dengan kebutuhan dan inventory di dalam tapak.
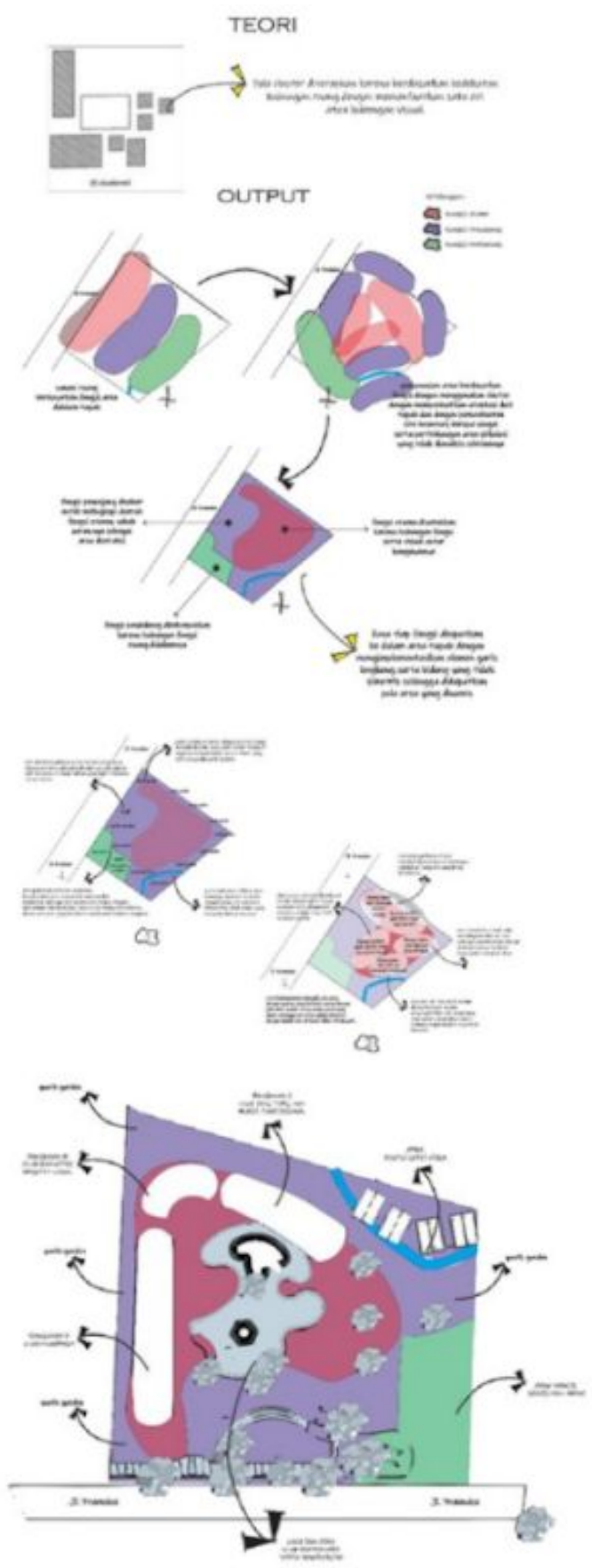

Gambar 5. Konsep Site

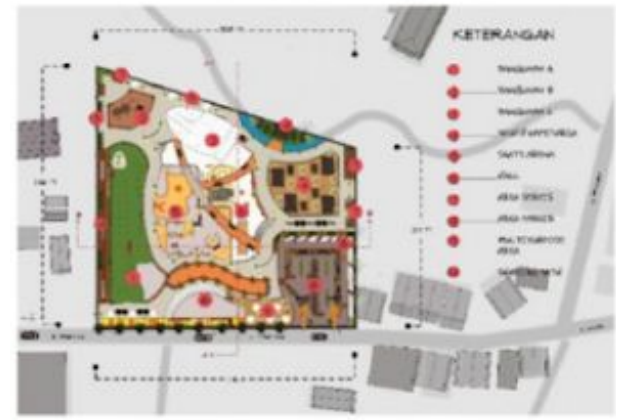

Gambar 6. Site Plan Youth Center 
2. Konsep Tata Massa

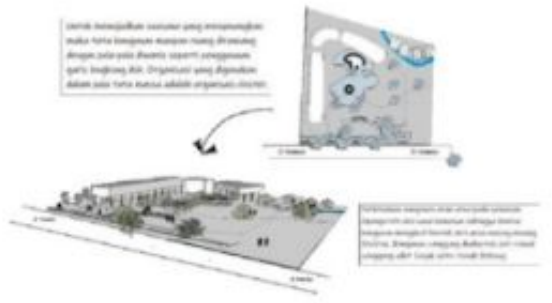

Gambar 7. Konsep Tata Massa

3. Konsep Massa

- Bangunan A

Bangunan A terdiri dari club panah, klub karate, club tenis meja, dan klub renang.

Fleksibilitas dan kedinamisan bangunan ini diwujudkan dengan pencampuran berbagai cabang klub dalam satu lantai dengan konsep ruang terbuka yaitu ruang bebas dinding di beberapa sisi bangunan. Kemudian dengan pengaplikasian warna yang cerah dan motif khas Dayak di beberapa bagian bangunan. Terdapat pula ruang santai yang disesuaikan dengan kebiasaan yang sering dilakukan oleh para remaja untuk tempat mereka nongkrong dsb.

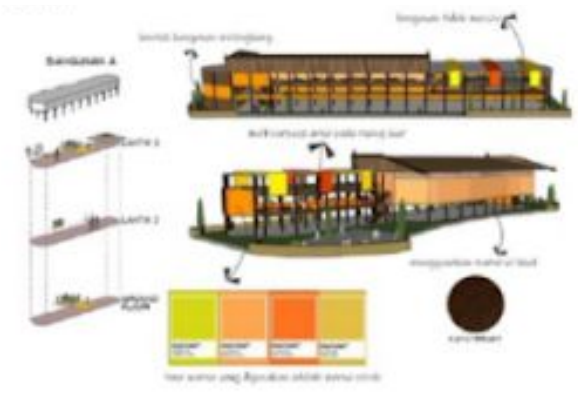

Gambar 8. Bangunan A

- Bangunan B

Bangunan $\mathrm{B}$ terdiri dari klub industri kreatif lokal dan klub seni lukis. Bangunan ini didesain dengan mengambil konsep seperti gazebo pada lantai 1 yang berisi fasilitas untuk latihan atau melihat proses kerajinan khas serta ruang santai serba guna yang dapat digunakan mereka untuk diskusi maupun hanya sekedar nongkrong. Sedangkan dilantai 2 diisi dengan ruang santai serba guna dan ruang kerajinan yang berperan untuk menarik remaja maupun pengunjung lainnya untuk berkunjung ke dalam kawasan dalam rangka memperkaya pengetahuan mereka tentang warisan budaya daerah.

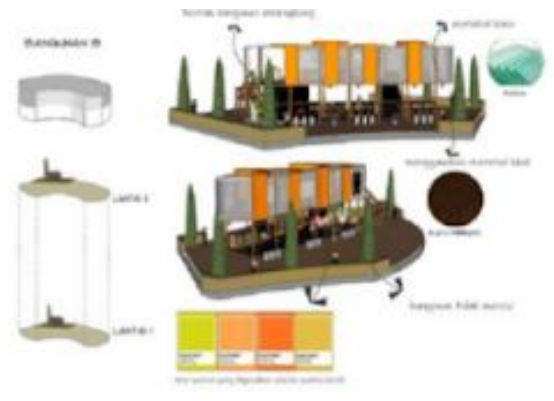

Gambar 9. Bangunan B

- Bangunan C

Bangunan $\mathrm{C}$ terdiri dari klub seni tari dan musik tradisional. Bangunan ini didesain dengan dinding yang tidak sepenuhnya masiv agar fleksibilitas bangunan dapat terwujudkan. Untuk menstimulasi semangat dari para pengguna digunakan warna-warna yang cerah dan motif motif khas Dayak agar remaja dapat semakin akrab dengan budaya daerah nya.

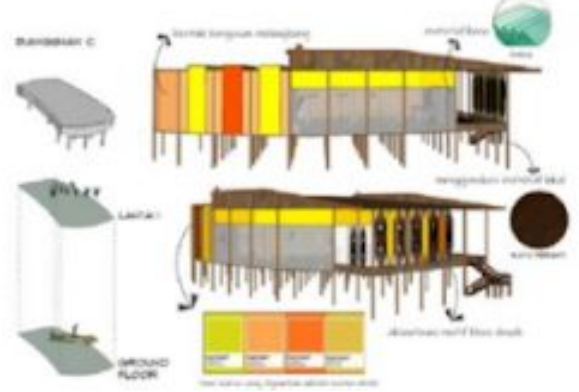

Gambar 10. Bangunan C

- Youth Cafetaria

Youth Cafeteria merupakan salah satu fasilitas penunjang yang berada di area sekitar aliran sungai dengan bentuk bangunan diambil dari tipologi bentuk jukung karena mengambil identitas dan suasana dari aliran sungai tersebut.

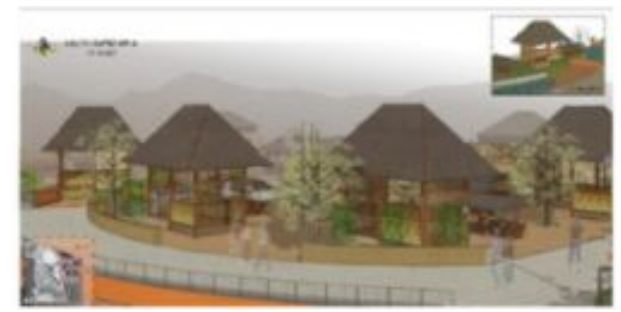

Gambar 11. Youth Cafetaria 


\section{Konsep Eksterior}

- Hall, Multipurpose Area, Sharing Wall, Mural Area dan Arena Skate Board

Hall, multipurpose area, sharing wall, dan mural area merupakan fasilitas penunjang sedangkan arena skateboard merupakan fasilitas utama di dalam youth center yang termasuk dalam perancangan ruang luar atau eksterior. Bentuk dari hall dan arena skateboard menggunakan bentuk yang dinamis dan abstrak melalui garis-garis yang melengkung, diikuti dengan sirkulasi yang cukup luas agar remaja dapat beraktivitas dengan bebas di dalam kawasan. Sharing wall merupakan wadah bagi para remaja untuk mengekspresikan ideas and emotions nya sedangkan mural area merupakan wadah yang disediakan agar para remaja dapat menyalurkan bakat lukis nya.

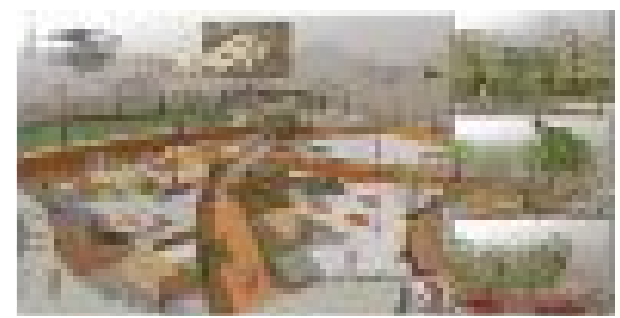

Gambar 12. Skate Arena dan Multipurpose Area

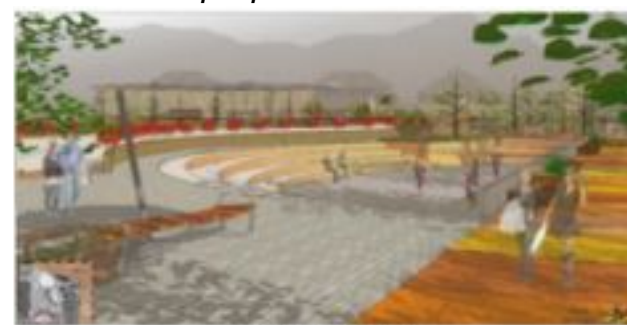

Gambar 13. Hall

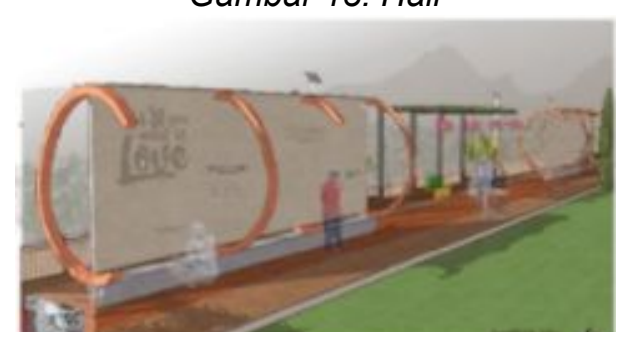

Gambar 14. Sharing Wall

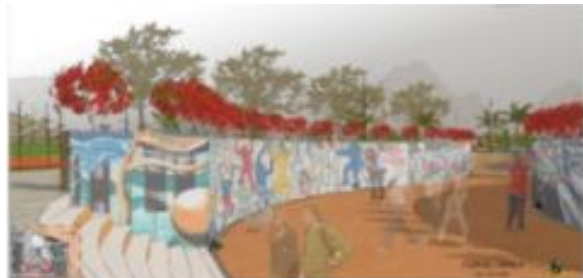

Gambar 15. Mural Area

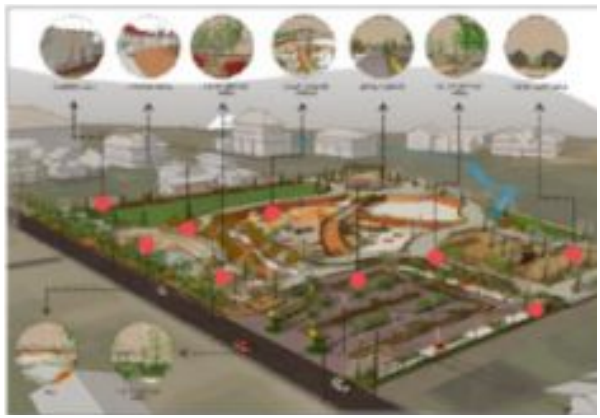

Gambar 16. Rencana Lanskap

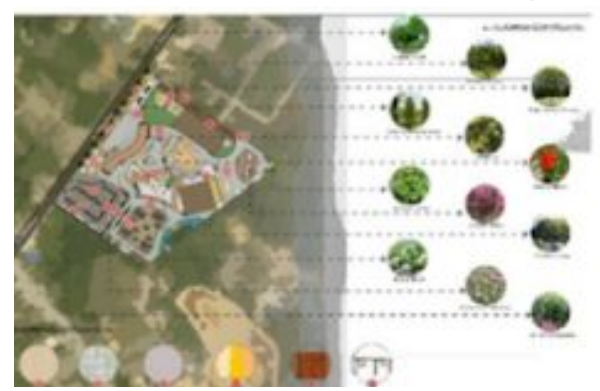

Gambar 17. Detail Lansekap

5. Konsep Interior

Interior ruang dalam bangunan disesuaikan dengan kebutuhan dari tiap-tiap klub yang ada didalam youth center. Dinding dicat dengan warna kuning atau oranye sehingga dapat menstimulasi suasana dan semangat saat berada di dalam ruangan serta penambahan elemen motif-motif khas Dayak untuk memperkuat konsep kawasan.

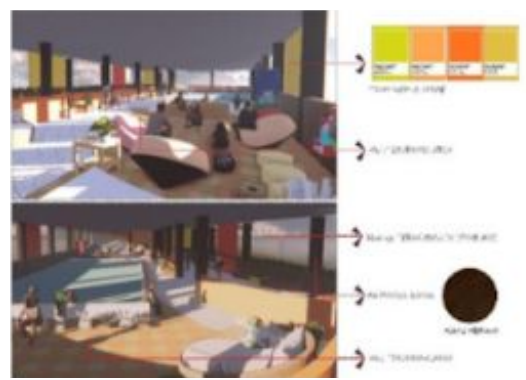

Gambar 18. Interior Bangunan A 


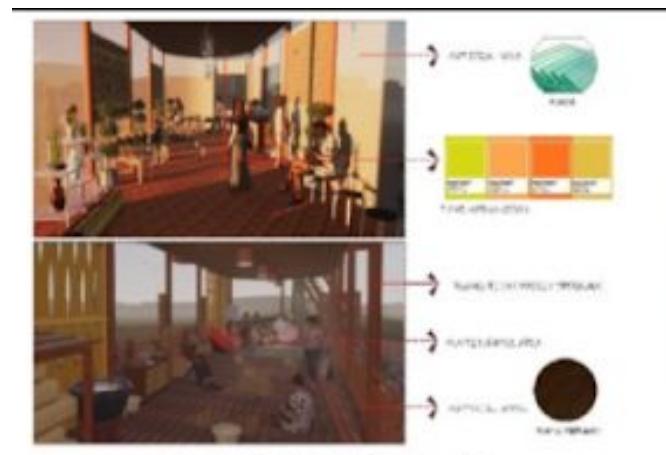

Gambar 19. Interior Bangunan B

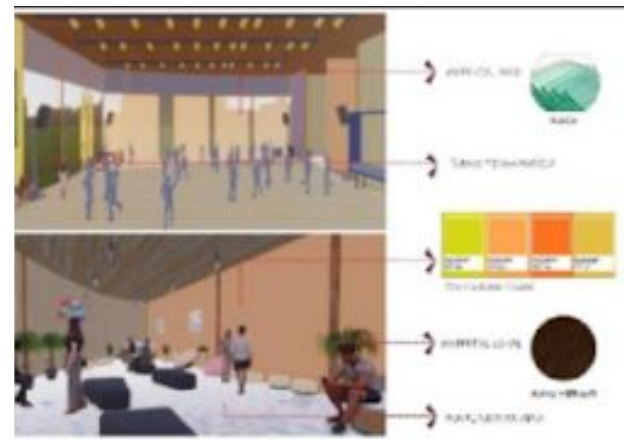

Gambar 20. Interior Bangunan C
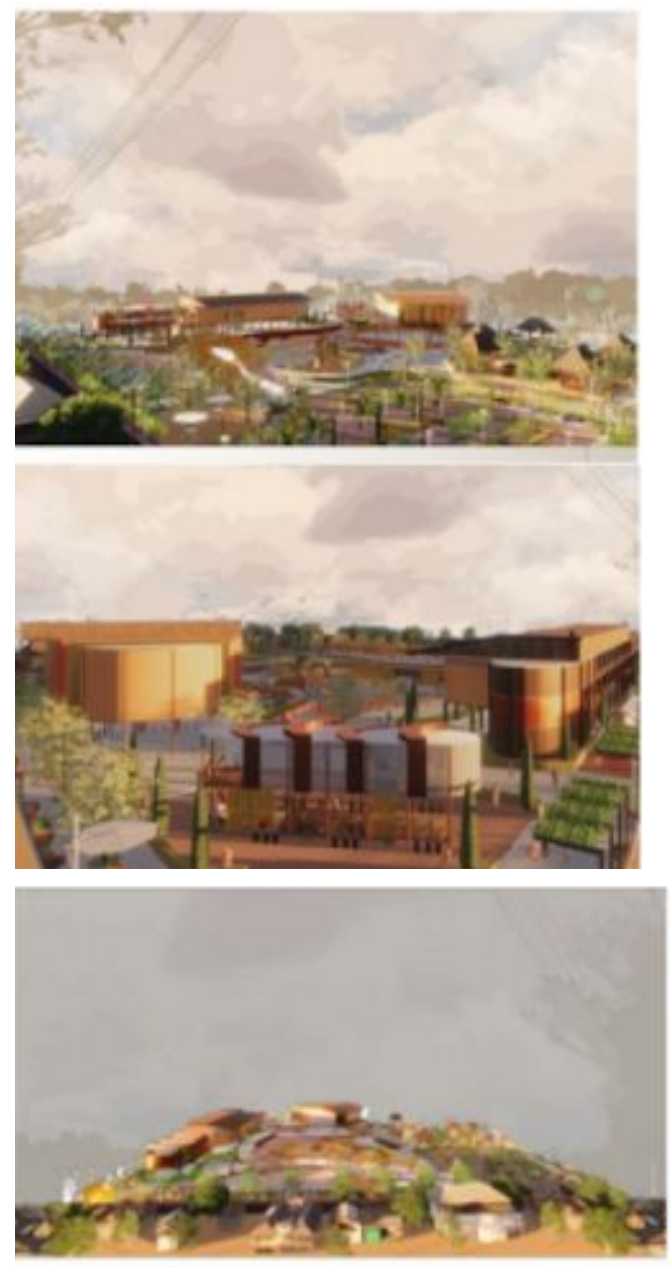
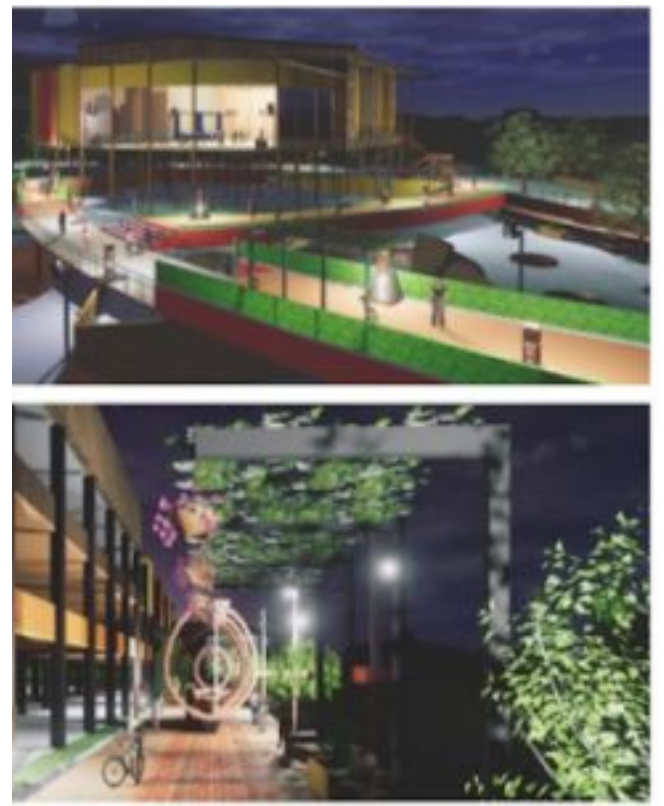

Gambar 21. Perspektif Kawasan

\section{KESIMPULAN}

Youth Center merupakan wadah untuk mengasah minat dan bakat para remaja khususnya pada bidang non-akademik. Didalam youth center terdapat berbagai klub yaitu diantaranya, klub olahraga, club seni dan klub industri kreatif lokal. Permasalahan yang ditemui diselesaikan melalui metode pendekatan psikologi arsitektur dengan mengkaji teori-teori dasar arsitektur yang dapat mempengaruhi kondisi psikis dan memunculkan suasana yang diinginkan baik didalam ruang maupun pada kawasan secara keseluruhan. Konsep yang digunakan yaitu Youth Cultural Space yang diterapkan pada elemen-elemen arsitektur. Perwujudan konsep tersebut diantaranya pada bentuk dan tata massa yang dinamis dan tidak kaku, ruang yang terbuka dan tidak massiv, pada pemilihan warna yang cerah yaitu gradasi warna kuning hingga oranye yang mampu menciptakan suasana ruang yang ceria dan bersemangat, pemilihan material kaca dan kayu yang memberikan kesan fleksibel dan alami, sirkulasi yang tersebar ke segala arah, serta ruang luar 
yang diisi dengan berbagai outdoor activity, space serbaguna serta vegetasi peneduh berbunga dan beraroma.

\section{DAFTAR PUSTAKA}

\section{Referensi Buku dan Jurnal}

Ching, F. D. (2000). Arsitektur Bentuk dan Susunannya. Jakarta: Erlangga.

Dipa, G. B. (201a. Tugas Akhir Sarjana Srata 1. Yogyakarta Youth Center Berkarakter Ekologis dengan Pendekatan Xeon Visual ApproPrianteness. Ernst, Neufert, (1987). Data Arsitek Jilid 1 Edisi Kedua, Jakarta: Erlangga.

\section{Website}

Nurhasanah, A. (2018, April 22). Psikologi Remaja, Karakteristik dan Permasalahannya. Retrieved May 8, 2019, from Pencarian Jati Diri pada Remaja:

https://www.kompasiana.com/an/57 19c1f41a7b61dc05c50cd9/psikologiremaja-karakteristik-danpermasalahannya?page=all

Surhayanto, A. (Ed.). (2018, November 1). 12 Hubungan Psikologi dengan Arsitektur. Retrieved Maret 18, 2019, from Dosen Psikologi: https://dosenpsikologi.com/hubungan-p sikologi-dengan-arsitektur

Tentang Barito Utara. (2018). Retrieved Maret 21, 2019, from Portal Resmi Kabupaten Barito Utara:

https://barltoutarakab.go.id/ 